\title{
A trajetória ininterrupta da reforma do aparelho de Estado no Brasil: Continuidades nos marcos do neoliberalismo e \\ do gerencialismo
}

\section{The uninterrupted path of the reform of the state apparatus in Brazil: continuities on the landmarks of neoliberalism and managerialism}

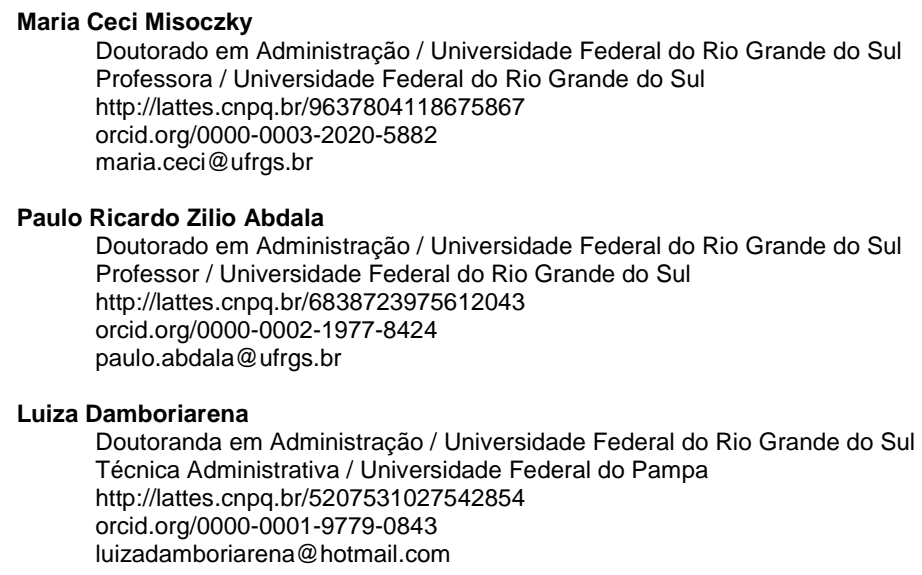

Resumo: O argumento deste ensaio é que tratar o neoliberalismo meramente como um programa de políticas e como um projeto monolítico constitui uma falácia que obstaculiza a compreensão do processo continuado de reformas do aparelho de Estado, que vêm ocorrendo desde o processo coordenado por BresserPereira e que teve como marco o Plano Diretor da Reforma do Aparelho de Estado de 1995. Em oposição a essa perspectiva restrita, conceituamos o neoliberalismo como um projeto de classe, um programa político dinâmico e resiliente que organiza a etapa atual do capitalismo, operacionalizado a partir do gerencialismo, uma racionalidade que propõe a reprodução da lógica de mercado em todas as dimensões da vida associada, operando como uma matriz teóricoideológica subsidiária. A articulação desse conjunto de ideias evidencia que o processo continuado de reformas de matriz neoliberal avança a partir do gerencialismo de maneira inexorável nas últimas décadas, independente dos partidos ou coalizões de governo.

Palavras Chave: Reforma do Estado, Neoliberalismo, Gerencialismo

Abstract: The argument of this essay is that treating neoliberalism merely as a policy program and as a monolithic project is a fallacy that hinders the comprehension of the continuing process of reform of the state apparatus that has been occurring since the process coordinated by Bresser-Pereira, and that has as landmark the 1995 Master Plan for the Reform of the State Apparatus. In opposition to this narrow perspective, we conceptualize neoliberalism as a class project, a dynamic and resilient political program that organizes the current stage of capitalism, operationalized from managerialism, a rationality that proposes the reproduction of market logic in all dimensions of the associated life, operating as a theoretical-ideological subsidiary matrix. The articulation of this set of ideas shows that the continuous process of neoliberal reforms has been inexorably advancing from the managerialism in the last decades, independently of the parties or coalitions of government.

Keywords: State reform. Neoliberalism. Managerialism.

\section{Introdução}

O argumento deste ensaio é que tratar o neoliberalismo meramente como um programa de políticas e como um projeto monolítico constitui uma falácia que obstaculiza a compreensão do processo continuado de reformas do aparelho de Estado, que vêm ocorrendo desde o processo coordenado por Bresser-Pereira e que teve como marco o Plano Diretor da Reforma do Aparelho de Estado de 1995. Falar do neoliberalismo como algo que passou e que ressurgiu após o golpe parlamentar de 31 de agosto de 2016, nega as evidências de que ele organizou, de maneira ininterrupta, práticas de governo, práticas no mercado e práticas sociais no
Texto completo em português: http://www.apgs.ufv.br Full text in Portuguese: http://www.apgs.ufv.br

sentido mais amplo. Além disso, permite o discurso falacioso de que seria possível um 'fora' ou 'acima' do neoliberalismo, como faz Bresser-Pereira (2008, p. 392), ao afirmar que sua reforma gerencial foi um "instrumento neutro, que tanto pode ser usado por uma administração conservadora, que deseja desmantelar o Estado social quanto por uma administração progressista que está preocupada com uma distribuição de renda mais igualitária na sociedade", ou que,

Do ponto de vista administrativo, a transição do Estado Burocrático para o Estado Gerencial, revelou-se um instrumento fundamental das sociedades modernas para neutralizar a ideologia neoliberal que buscava diminuir o tamanho do Estado, na medida em que, ao 
tornar mais eficiente (embora jamais tão eficiente como gostaríamos) a provisão dos serviços sociais públicos ou coletivos, legitima o próprio Estado Social, e garante seu aprofundamento futuro" (Bresser-Pereira, 2010, p. 116).

Bresser-Pereira quer fazer crer que a reforma do aparelho de Estado pode ser compreendida fora do contexto histórico do padrão de acumulação do capitalismo.

Outro argumento falacioso decorrente do tratamento equivocado do neoliberalismo se refere à suposta existência de governos pós-neoliberais. Sader (2013, p. 138), p. ex., defende que "os governos do Lula e da Dilma podem ser caracterizados como pós-neoliberais, pelos elementos centrais de ruptura com o modelo neoliberal - de Collor, Itamar e FHC - e pelos elementos que têm em comum com outros governos da região". Ainda que admita que "o modelo neoliberal siga dominante em escala mundial", o autor entende que os governos petistas seguiram na contramão das tendências mundiais, construindo políticas anticíclicas baseadas em três eixos: (1) priorização das políticas sociais, (2) priorização dos processos de integração regional, e (3) priorização do papel do Estado como indutor do crescimento econômico e da distribuição de renda.

Estes equívocos decorrem, usualmente, da adoção de um raciocínio simplificador que iguala neoliberalismo a Consenso de Washington e enfatiza, centralmente, o tema da redução do tamanho do aparelho de Estado a partir de reformas gerenciais. Um exemplo é a afirmação de Bresser-Pereira (2010, p. 115) que, para contestar as críticas de que a reforma por ele iniciada seria neoliberal, diz: "ficou claro que sua consequência primeira foi fortalecer o próprio Estado, e não enfraquecê-lo como almejavam os neoliberais".

Esclarecer a dinâmica e resiliência do neoliberalismo como programa político que organiza a etapa atual do capitalismo nos permitirá tratar, na sequência deste ensaio, o gerencialismo como seu braço operacional. Para compreender o obscurecimento da relação entre neoliberalismo e reformas gerenciais, recorremos ao próprio Bresser-Pereira. Finalmente, articulamos esses três conjuntos de ideias nas Considerações Finais, na qual buscamos evidenciar o processo continuado de reformas de matriz neoliberal, que avançam a partir do gerencialismo de maneira inexorável nas últimas décadas, independente dos partidos ou coalizões de governo.

\section{Neoliberalismo: vertentes e renovação}

Os marcos fundantes da emergência do neoliberalismo são o ano de 1947, com a criação da Sociedade de Mont-Pèlerin (nascimento in vitro); o ano de 1973, com o golpe de Estado contra o governo Salvador Allende no Chile, que transforma aquele país em um laboratório experimental (nascimento in vivo); e o Consenso de Washington, em sua versão de 1989, e seus sucedâneos agenciados pelos organismos multilaterais de crédito (PuelloSocarrás, 2013a, p. 16-17).

O Consenso de Washington 89 (CW-89) prescreveu dez medidas: disciplina fiscal; redução dos gastos públicos; reforma tributária; liberalização financeira; taxa de câmbio competitiva; abertura do mercado interno; eliminação de restrições ao capital externo; privatização; desregulamentação; e direito de propriedade (Williansom, 2004). Sob a alegação de que o CW-89 tinha um viés economicista, voltado para aspectos macroeconômicos, e que seus resultados intensificaram os níveis de pobreza e miséria nos países em desenvolvimento, emergiu um movimento supostamente antineoliberal de revisão pelos próprios órgãos de enunciação, como o Banco Interamericano de Desenvolvimento (BID) e o Banco Mundial (BM). A publicação do livro "El desarrollo económico y social en los umbrales del siglo XXI", em 1998, pelo BID, inseriu novos temas, como o fortalecimento institucional e a educação. $O$ BM, através do relatório "Más allá del Consenso de Washington: la hora de la reforma", destacou a necessidade de implantar uma segunda geração de reformas, o "Consenso de Washington Ampliado". Em 1998, emergiu o "Consenso Pós-Washington" (Stinglitz, 1998), segundo o qual a incompletude e os equívocos do CW-89 levaram à necessidade de metas mais amplas, que visassem o crescimento econômico de longo prazo, o bom desenvolvimento institucional e regulatório do sistema financeiro, a correção das falhas do mercado sob a complementaridade estatal, e uma maior eficiência dos governos para garantir o êxito da economia de mercado. Na sequência, em 2001, foi divulgado o "Dissenso de Washington", através do informe "Políticas económicas para la equidad social en Latinoamérica", enfatizando a equidade e a redução da pobreza, e oferecendo "10 + 1" ferramentas de política, em alusão aos 10 princípios do CW-89: disciplina fiscal baseada em regras; amenizar os efeitos cíclicos de expansão e colapso; redes de segurança ativadas automaticamente; escola para os pobres; taxar os ricos; dar oportunidades às pequenas empresas; fortalecer os direitos dos trabalhadores; lutar contra a discriminação; parar o mercado de terras; serviços públicos orientados ao consumidor; e reduzir o protecionismo dos países desenvolvidos (Birdsall \& La Torre, 2001). Essas sucessões de documentos, desde o CW-89 até o Dissenso em 2001, representaram uma resposta à agenda emergente de reivindicações frente aos efeitos nocivos do neoliberalismo e implicaram em uma série de mudanças nas prescrições de reformas econômicas e políticas. Porém, o fato é que todos reproduziam a mesma essência, adaptando-a para a persistência e renovação do projeto neoliberal (Puello-Socarrás \& Gunturiz, 2013).

Como alerta Puello-Socarrás (2015a, p. 23), o neoliberalismo "é um projeto político de classe, não apenas um programa de políticas", e não se "esgota nem se pode equiparar exclusivamente com o Consenso de Washington", nem com sua versão original, nem com os sucedâneos. Seu conteúdo representa apenas uma das diversas tradições históricas do projeto neoliberal, considerado como uma etapa do capitalismo na qual se pode observar "a mais pronunciada exacerbação das lógicas e contradições inerentes à reprodução e acumulação incessante do capital" (Puello-Socarrás, 2013a, p. 14). Limitá-lo, portanto, a um programa de políticas "oculta e minimiza seu significado sócio-político".

Harvey (2007, p. 10) explica que o neoliberalismo surgiu como projeto utópico (a utopia do mercado total) na tentativa de 
reorganizar o capitalismo internacional após a queda da socialdemocracia europeia e dos modelos de substituição de importações nos países periféricos, mas também como um "projeto político visando tanto reestabelecer as condições para acumulação de capital como restaurar o poder de classe". A crise de acumulação dos anos 1970 parecia abrir cada vez mais espaço para o surgimento de uma alternativa socialista, apontada por movimentos sociais urbanos e parte da população trabalhadora, mesmo nos países ditos desenvolvidos. Naquele contexto, o neoliberalismo, que pouco conseguiu em termos de uma efetiva retomada do crescimento da taxa de acumulação, criou uma eficiente "utopia teórica discursiva que serviu como sistema de justificação e legitimação".

Sendo um projeto econômico-político transnacional da classe capitalista, seu carreador mais potente é uma estratégia de acumulação específica chamada comumente de 'desenvolvimento'. No estágio atual da história, tal estratégia se vincula com a generalização da mercantilização e se materializa em táticas a partir de diferentes programas de políticas, inclusive econômicas, mas não somente. Assim, análises que focam no nível da estrutura organizacional do aparelho de Estado ou das políticas públicas, sem evidenciar sua articulação com as transformações na matriz orientadora do chamado desenvolvimento, ficam restritas à dimensão tática, tendo pouca capacidade para explicar a realidade (Puello-Socarrás, 2015a).

Antes de avançar, é preciso esclarecer que o neoliberalismo não é um corpo monolítico de proposições. Ao considerar os aspectos teóricos, as práticas históricas, as fontes ideacionais e as filiações políticas, ideológicas e sociais, Puello-Socarrás (2008 e 2015a) identifica cinco referências básicas do pensamento neoliberal, que reproduzimos nos próximos itens:

a) A Escola Neoclássica Anglo-Americana é representada pela Escola de Cambridge e Londres e, mais reconhecidamente, pelas últimas gerações da Escola de Chicago, sob a liderança de Milton Friedman (é a corrente ortodoxa) - a economia é a ciência da escassez e do intercâmbio simples, incluindo uma teoria da decisão com um conceito reduzido do econômico e uma noção estreita de racionalidade. As correntes apresentadas na sequência são consideradas, por essa, como heterodoxas.

b) Escola Neoclássica Austríaca, particularmente a de Viena (liderada por Mises e Hayek, mas incluindo, p. ex., Schumpeter e Rosenstein-Rodan') e seus sucedâneos geracionais - a economia é a ciência da ação humana e dos intercâmbios sociais complexos, sob a égide da racionalidade.

c) Neoliberalismo Alemão - Ordo-liberalismo e Escola de Economia Social de Mercado (ESM) - critica o laissez-faire do liberalismo clássico e sua manifestação no neoliberalismo ortodoxo, afirmando que nenhuma sociedade poderia funcionar harmônica e perfeitamente graças aos automatismos do mercado. Isso não significa abandonar a ideia de que o mercado seja primordial; significa aceitar que é imperfeito e que a exagerada liberdade (libertinagem) é danosa e indesejável, inclusive por suas implicações sociais negativas que até poderiam colocar em risco a continuidade do sistema capitalista como um todo. Defendem, portanto, que o mercado deve ser seletivamente regulado e, mesmo, corrigido, sem, no entanto, ser dirigido ou planificado (o lema é 'Estado forte, economia livre'). Propõe a construção de uma ESM que, claro, tem mais de mercado e menos de social. Para construí-la, seria preciso reconciliar essa liberdade com a atenção aos problemas sociais que as próprias lógicas mercantis geram ii.

d) As Sínteses Neoclássico-Keynesianas - harmonizam os pressupostos neoclássicos com a teoria keynesiana, ainda que isso possa parecer um paradoxo pelas diferenças conceituais, visto que para Keynes existe uma série de obstáculos, principalmente em termos de salários, que impossibilitam um equilíbrio geral, o que seria contrário aos postulados neoclássicos de concorrência perfeita. As sínteses reconhecem as imperfeições dos mercados e admitem uma intervenção estatal em dose mínima e dirigida ao mercado.

e) As Sínteses Austro-americanas e Americano-austríacas mesclam elementos das correntes anglo-americanas e austríacas. A síntese americano-austríaca se expressa no neoinstitucionalismo econômico e na teoria da escolha pública. O objetivo das sínteses é unificar e equilibrar, na mesma base epistêmica, elementos neoclássicos austríacos e americanos, condensando aspectos políticos e institucionais.

As diferenças entre as correntes são teóricas, epistemológicas e metodológicas, e também interpretações diferentes em termos de ações políticas e econômicas. Cabe ainda, destacar que:

[...] mais além das diferenças teóricas que existem ao comparar posições ortodoxas e heterodoxas que, em abstrato, seriam opostas (quase antípodas ainda que nunca contraditórias), ambas mantêm em uníssono os princípios gerais do neoliberalismo e convergem superando suas diferenças - em uma unidade ideológica consistente que guia suas práticas fundamentais. [...] além do dissenso abstrato, o neoliberalismo in extenso conflui politicamente ao redor de um acordo fundamental de princípios "em concreto", o qual - no dizer do próprio Hayek, discute, mas não questiona "certos conceitos básicos", fundamentalmente a construção da sociedade de mercado (não apenas da economia de mercado). Para todos os neoliberais, os problemas da sociedade, as dinâmicas públicas e as tensões e conflitos sociais devem ser sancionados e considerados univocamente sob uma ótica individualista no mercado (PuelloSocarrás, 2015a, p. 26).

As diferentes vertentes já indicam que o neoliberalismo é dinâmico. Destacamos que também é resiliente, capaz de enfrentar desafios e críticas e se renovar. Pode-se, então, falar em um neoliberalismo que resulta do processo de transformação para superar resistências e se fundamenta em dois elementos cruciais: (1) uma roupagem mais heterodoxa, que permite regenerar estrategicamente sua imagem perante a sociedade, incorporando parte das críticas anti-neoliberais dos anos 1990, inclusive sociais, políticas e ecológicas; e (2) “a aceitação de que o capitalismo em geral e o neoliberalismo em específico não poderiam funcionar sem a presença relativamente ativa do Estado-Nação (a qual, recordemos, é uma produção histórica do capitalismo)" (PuelloSocarrás, 2015a, p. 35).

Cabe aqui um espaço para uma breve menção ao antineoliberalismo na história recente de países da América do Sul. Segundo Puello-Socarrás (2013b), entre as décadas de 1970 e 1990, houve pelo menos doze governos claramente identificados 
com o neoliberalismo na América Latina e Caribe. O aumento dos protestos sociais e a renovação eleitoral, com a vitória de projetos políticos localizados ao centro e à esquerda dos cenários partidários, consolidaram uma chamada onda antineoliberal. Em decorrência, nos meios acadêmicos, mídia e discursos políticos, surge a afirmação de que existiriam governos pós-neoliberais (ver, p. ex., Sader, 2008; MacDonald \& Ruckert, 2009).

Para expressar uma posição a esse respeito é preciso acompanhar o raciocínio de Puello-Socarrás (2013b) e esclarecer sucintamente o que não é e o que é o neoliberalismo. Ele não é unicamente um conjunto de políticas econômicas ou sociais, um programa de políticas associado às prescrições do CW-89; e não é monolítico, como já mencionamos, desde seu surgimento podem ser reconhecidas variantes, ainda que a principal corrente entre os 1970 e 1990 tenha sido marcada pela ortodoxia. Portanto, para falar do final ou de um pós-neoliberalismo é preciso considerar o conjunto das vertentes. Para facilitar, consideremos duas variantes centrais: o 'velho' e ortodoxo, baseado no fundamentalismo de mercado, e o 'novo' e heterodoxo, para o qual o mercado é fundamental (Puello-Socarrás, 2008 e 2015a).

É reconhecível que as críticas, os protestos e as plataformas político-partidárias antineoliberais se dirigiam ao 'velho' e ortodoxo, e que o processo histórico em muitos países da região levou, de fato, ao final da hegemonia ortodoxa neoliberal. Falta esclarecer porque argumentamos que esse processo levou, também, ao renascimento do neoliberalismo, desta vez renovado e de inspiração heterodoxa. Ou seja, porque se trata de um processo de "continuidades e descontinuidades em perspectiva histórica e política”, em vez da dicotomia continuidades ou descontinuidades (Puello-Socarrás, 2013b, p. 175).

Nas palavras de Puello-Socarrás (2013b, p. 181):

Substancialmente, o critério básico para avaliar - analítica e politicamente - os regimes pró e anti-neoliberais é a força contrahegemônica dos projetos políticos e as trajetórias em políticas, associadas com a efetiva transformação do paradigma baseado no mercado que afeta os discursos em geral e as práticas específicas dos regimes de desenvolvimento em cada um dos casos (países) e, posteriormente, na reconfiguração do conjunto (regional), mediante um estudo que percorra os diferentes níveis 'de cima para baixo' e 'de baixo para cima'. Sob esse enfoque, por exemplo, os 'modelos' econômicos regionais, como o chamado 'neodesenvolvimentismo', são marcadamente pró-neoliberais e representam simplesmente uma continuidade no curso do renascimento neoliberal no século $\mathrm{XXI}$.

Gambina (2015, p. 91) ajuda a esclarecer esta última afirmação. O autor analisa o conjunto de países/governos latino-americanos que poderiam ser considerados críticos à ordem neoliberalisadora e os divide em dois grupos. Em um conjunto, países que "nunca se propuseram um horizonte anti-sistêmico, mas apenas a recuperação do funcionamento da ordem capitalista" - Brasil, Uruguai e Argentina; em outro, países nos quais predominou a crítica ao modelo de desenvolvimento neoliberal - Bolívia, Equador e Venezuela. No entanto, o papel do Estado continua sendo o de assegurar o funcionamento do ciclo do capital aprofundando, para tanto,
A primarização via monocultura da soja (transgênica) com domínio das transnacionais da alimentação ou da biotecnologia; a megamineração a céu aberto com ampla hegemonia de capitais e tecnologia externos, incluindo o desenvolvimento petroleiro e gasífero (Gambina, 2015, p. 91).

Fácil fazer transposições desta descrição ao caso do Brasil, apenas com a diferença de que aqui se encontra ausente a problematização do modelo de desenvolvimento.

Entendemos, portanto, que não se pode apresentar o regresso do Estado como uma evidência do pós-neoliberalismo. De fato, além das macropolíticas, como as mencionadas acima, é preciso levar em consideração sua expressão operacional em novas formas de atuação institucional e de organização de políticas públicas com base nas tecnologias que compõem a Nnova Aadministração Ppública (NAP) e nos seus desdobramentos e renovação, tais como a governança em suas diferentes versões, as parcerias de bens comuns na lógica de Ostrom (1990), os governos empreendedores e o empreendedorismo. Esses são alguns "exemplos cruciais emergentes na atualidade [...] sobre os quais não se reflete teoricamente nem se trata politicamente de forma sistemática". No tratamento de temas como os mencionados, se omite, em geral, o fato de que são expressões "das variantes do neoliberalismo em suas versões heterodoxas e, portanto, não representam senão uma continuidade 'crítica', mas renovada que reforça o projeto socioeconômico e político vigente" (Puello-Socarrás, 2015b, p. 41).

Para finalizar esta parte é preciso, ainda, mencionar as críticas neoliberais ao neoliberalismo, porque elas explicam grande parte das mudanças no seu interior, de maneira a garantir que fique intacta "a convicção de que o mercado deve ser o critério ordenador onipresente e (re)produtor da totalidade das dinâmicas sociais" (Puello-Socarrás, 2016, p. 7). Alguns exemplos: (1) o governo dos bens comuns, já mencionado que, com essa denominação tentadora, encobre a gestão privada do comum, por meio de espaços sociais público-privados que funcionam pela lógica do mercado e regulados pelo Estado (Ostrom, 1990); (2) a regulação da economia de mercado para paliar certas falhas que lhe são inerentes e garantir a competição, ou seja, regras claras e reguladores independentes para uma liberalização eficaz (Tirole, 2005); e o tão conhecido Stinglitz (1998), autor do Consenso PósWashington, que se opõe aos acordos de livre comércio TransAtlântico e Trans-Pacífico porque "não criaram um regime de livre comércio autêntico". Complementando a análise destes autores e, especificamente do último, Puello-Socarrás (2016, p. 11) sintetiza:

Convergindo com o Vaticano, Merkel, Friedman e Pinochet, Stinglitz se inscreve, também, na mesma linha de argumentação própria das correntes neoliberais heterodoxas, que criticaram ferreamente a desregulação e a libertinagem dos mercados [...], tanto como o poder dos monopolistas.

O autor prossegue, "este pensamento neoliberal crítico do neoliberalismo defende a presença estatal em função de uma economia 'regulada' (ainda que não dirigida, o que é distinto)", interpretando-o como "economia social de mercado". Nela, a competição é o princípio fundamental de coordenação e se 
"combinam, sobre a base desta economia competitiva, a livre iniciativa com avanços sociais" (Puello-Socarrás, 2016, p. 11 e 19).

\section{Gerencialismo: braço operacional e ideologia complementar do neoliberalismo}

Sintetizando o argumento desenvolvido no item anterior, lembremos, com a ajuda de Puello-Socarrás (2015a, p. 22) que, "desde a década de 1970 e até o dia de hoje, o neoliberalismo é, por antonomásia, a estratégia ofensiva e contrarrevolucionária do capital (contra o trabalho)". Por isso, o neoliberalismo "deve ser concebido como uma 'reação' (também: 'saída' e 'solução' para as elites econômicas e políticas mundiais) com o fim de afrontar a crise estrutural e global do capitalismo tardio". Por se tratar de uma ideologia com função de renovação do poder de classe, o neoliberalismo não poderia ter um caráter estático e, portanto, precisa se renovar para manter sua eficiência. Nesse sentido, é identificável uma primeira versão, que enfatizava a desregulamentação dos mercados (1970-2000), e uma nova síntese, que enfatiza a economia social de mercado (desde o início dos anos 2000).

Para que fique claro ao que nos referimos, definimos ideologia nos termos propostos por Lukács (2012), para quem a ideologia é ideológica precisamente porque cumpre uma função e produz efeitos concretos nos processos reais. Ou seja, a ideologia pode se expressar na forma de ideia ou de atividade prática, mas sempre tem uma função na reprodução social. A ideologia é uma forma de elaboração ideal da realidade que serve para tornar a prática dos homens consciente e operativa, manifestando-se na vida social de modo permanente e sendo uma possibilidade criada pelas circunstâncias histórico-sociais a partir das necessidades da vida cotidiana. Portanto, ideologia e existência social são realidades inseparáveis. A concepção de ideologia como função desloca o foco do critério gnosiológico-científico (do verdadeiro ou falso) para o critério ontológico-prático (a função social que desempenha).

De acordo com Misoczky (2016), o gerencialismo se constitui em uma racionalidade que justifica e propõe a reprodução da lógica de mercado em todas as dimensões da vida associada, operando como uma matriz teórico-ideológica subsidiária do neoliberalismo, com uma função organizadora das práticas sob a égide do mercado. No entanto, há uma tendência, no campo da Administração Pública (AP), de tratá-lo como um fenômeno circunscrito à contaminação do público pelo privado, ainda que essa contaminação seja uma das dimensões deste fenômeno.

Em outro trabalho, Misoczky (2014, p. 8-9) retoma as marcas de nascença da AP, que continuam hegemônicas em sua trajetória histórica, como apoio para compreender a facilidade com que, "nas últimas décadas, a lógica da administração empresarial e o valor do empreendedorismo" (em outras palavras, ideias fundamentais do neoliberalismo) "invadiram praticamente sem resistências os espaços da AP" (Misoczky, 2014, p. 12). A autora demonstra como o ensaio seminal de Woodrow Wilson (1953), publicado em 1887, já afirmava a separação entre política e administração, bem como a eficiência como categoria central. Desde então, o que se encontra, predominantemente, é um campo disciplinar impregnado pela "hipervalorização do mercado e por uma cultura individualista". A autora também recorre às afirmações de Simon, Smithburg e Thompson (1959, p. 7) para confirmar a marca de origem da AP nos EUA, a partir do qual se dissemina para nosso contexto. Segundo esses autores, a AP seria uma área da administração que se diferencia unicamente por seu objeto de estudo: organizações operativas dos "negócios do Estado". Segundo Misoczky (2014, p. 11), a influência de Simon (1947) "sedimenta a centralidade da racionalidade instrumental na AP". Além disso, "sob sua liderança, é buscada uma abordagem cientificista - uma abordagem puramente preocupada com afirmações factuais na qual não existe base para afirmativas éticas: política e administração foram separadas". Um exemplo muito óbvio desta persistente separação é a afirmação de Bresser-Pereira (2008) sobre a reforma gerencial como instrumento neutro (citada na Introdução deste artigo).

Abrimos aqui um espaço para, com a ajuda de Fadul, MacAlilister da Silva e Silva (2012, p. 1439), lembrar que o campo da AP no Brasil "nasce e se desenvolve atrelado à própria AP federal", com amarrações que constrangem o campo, "limitando-o aos temas que estão em evidência no contexto governamental, em análises que se repetem, quando não apenas descrevem o que vem ocorrendo no setor público". Os autores constataram, ainda, ao analisar a pesquisa em AP, "a existência de dificuldades teóricas, conceituais e metodológicas", incluindo a confusão entre referencial teórico e contextualização; uma natureza mais prescritiva que analítica, contaminada por um viés normativo; "a existência de poucos estudos teóricos e de escassos estudos realizados em profundidade; a utilização ampla e generalizada de estudos de caso; [...] a dificuldade sistemática do referencial teórico com o estudo empírico; além da generalização rápida de achados" (Fadul, Silva \& Silva, 2012, p. 1450). Essas tendências continuam vigentes. Ao escrever este texto revisamos os artigos publicados (167) nos últimos três anos na Revista de Administração Pública. Encontramos apenas oito ensaios teóricos, sendo a maioria dos trabalhos estudos de caso ou relato de experiências. Talvez uma das razões desta fragilidade teórica decorra do afastamento voluntário dos estudiosos da AP das Teorias Organizacionais (TOs), no campo mais amplo da Administração.

Voltando ao tema do gerencialismo, recordemos, por exemplo, que Tragtenberg (1980) o criticou no exato momento em que ele começava sua trajetória, reconhecendo, já nos anos 1970, que a constante utilização da palavra management tinha o objetivo de esconder os conflitos e as dificuldades psicológicas sob a suposição de relações organizadas pela técnica neutra e eficiente.

Para discutir seu significado, Misoczky (2016, p. 14) parte de um diálogo com Prestes Motta (2001) e propõe a existência de "uma segunda mutação das TOs convencionais, sob o neoliberalismo, definida pela emergência do gerencialismo, seu braço operacional e ideologia complementar". A primeira mutação, segundo Prestes Motta (2001), ocorreu no período após a II Guerra Mundial. Diz ele a esse respeito: "a teoria das organizações é fruto de uma mutação 
da teoria da administração, a partir da evolução sociológica, ciência política e psicologia social norte-americanas".

A segunda mutação, segundo Misoczky (2016, p. 17), se

Expressa na passagem para o gerencialismo - uma forma específica de racionalidade que, como já mencionamos, reproduz em todas as dimensões da vida associada a lógica das relações específicas de mercado e se constitui em uma ideologia porque, além de mistificar contradições específicas do capitalismo operando no nível das ideias, também se expressa concretamente no nível prático da vida cotidiana (Misoczky, 2016, p. 17).

Segundo Klikauer (2013, p. 1105),

O gerencialismo combina conhecimento e ferramentas genéricas do management para estabelecer-se sistematicamente nas organizações, nas instituições públicas e na sociedade, ao mesmo tempo em que priva os donos dos negócios (propriedade), os trabalhadores (econômico-organizacional) e a sociedade civil (sócio-política) de todo o poder decisório. O gerencialismo justifica a aplicação de suas técnicas gerencias em todas as áreas de trabalho e em toda a sociedade capitalista com base em superioridade ideológica, no treinamento de competências e na exclusividade do conhecimento gerencial necessário para fazer funcionar instituições públicas e a sociedade como se fossem corporações.

A emergência do gerencialismo também precisa ser compreendida como parte da estratégia de classe para contrarrestar a crise do capitalismo que se iniciou na década de 1970. Às TOs convencionais também cabia renovar-se para continuar cumprindo sua função de suporte às transformações das relações sociais de produção. Nesse sentido, não se pode ignorar a importância de Peter Drucker. Novamente, foi Tragtenberg (1980, p. 12-13) quem reconheceu o papel desse ideólogo no momento histórico em que suas proposições se disseminavam. Vale a pena citá-lo:

Para Drucker, o povo organizado na sociedade sem classes norteamericana constitui uma realidade; o capitalismo dissolve a classe operária e proletária, criando um povo-classe média. Isso é possível pela união de burocratas, técnicos e gerentes vinculados ao proprietário. Em síntese, Drucker caracteriza a sociedade industrial pela inexistência da luta de classe, já que existe apenas uma - o povo classe média vinculado às grandes corporações. Nesta proposição se identifica uma ideologia neocapitalista, cuja função é a legitimação do status quo como o único possível e desejável (Tragtenberg, 1980, p. 12-13).

A leitura de Drucker (1999, p. xv-xvi), em um texto no qual visita sua própria trajetória, deixa patentemente clara a ligação de suas proposições com o neoliberalismo:

A mudança para a sociedade pós-capitalista teve início pouco depois da Segunda Guerra Mundial. Escrevi, pela primeira vez, sobre uma sociedade dos empregados antes de 1950. Dez anos depois, pelo ano de 1960, criei as expressões 'trabalho do conhecimento' e 'trabalhador do conhecimento'. Em $A$ idade da descontinuidade (1969) falei, pela primeira vez, de 'sociedade de organizações'. [...] Foi somente com o colapso do comunismo como ideologia e do comunismo como sistema, que ficou completamente claro que havíamos adentrado em uma sociedade nova e diferente. [...] A nova sociedade [...] irá usar o livre mercado como mecanismo comprovado de integração econômica.

Ou seja, para compreender a mutação da administração para a gestão é indispensável reconhecer a importância de Drucker como ideólogo do capitalismo, como fez Tragtenberg (1980). O entendimento dessa segunda mutação das TOs permite compreender o gerencialismo e, em decorrência, o processo de reformas da AP brasileira como parte de um contexto mais amplo que se define como um projeto político de classe em um determinado momento histórico de desenvolvimento do capitalismo, superando sua análise como mera racionalidade técnica que orienta um modelo de gestão para o aparelho do Estado.

Feitos estes esclarecimentos, podemos agora tratar especificamente da NAP, afirmando-a como um conjunto de técnicas e tecnologias de gestão que operacionalizam, na organização do aparelho de Estado, o projeto político neoliberal e o gerencialismo. A NAP - teoria unificadora, geral e normativa - se dissemina a partir dos países centrais anglo-saxões, com apoio das agências internacionais de financiamento e cooperação - e suas prescrições (visão gerencial de Estado, ênfase nas relações contratuais, privatizações, cidadão-cliente, descentralização, gestão por resultados, flexibilização das relações de trabalho, articulação entre público e privado e empreendedorismo como valor, entre outras) funcionam como matriz para processos de reforma implementados, com nuances decorrentes de especificidades nacionais e momento histórico, desde os anos 1980 (Puello-Socarrás, 2014).

Entretanto, o que se encontra, predominantemente, nos textos mais analíticos sobre a reforma do aparelho de Estado é uma associação direta entre a existência do neoliberalismo, em sua visão restritiva, e do gerencialismo, pela adoção dos termos mais gerais da NAP (Andrews, 2010). Tal perspectiva entende a reforma dos anos 1990 como um episódio historicamente localizado, ainda que por vezes admitindo insuficiências e consequências presentes (Fadul \& Silva, 2008), e não como um projeto sócio-político relacionado à etapa neoliberal do capitalismo e ao gerencialismo como seu braço operacional. Para reforçar essa constatação, uma busca na Revista de Administração Públicaiii pela palavra neoliberalismo nos títulos e resumos de artigos não tem sucesso, resultado repetido nos encontros da Anpad, enquanto o termo "reforma do Estado" retorna 105 itens.

\section{E a reforma continuada do aparelho de Estado?}

A reforma do aparelho de Estado teve, no Brasil, um caráter para além do que se convenciona chamar de reforma administrativa (mero ajustamento organizacional a novas ou modificadas atribuições); constituindo-se, de fato, em uma "alteração da propriedade e da relação entre propriedade privada e propriedade estatal", como destaca Alves (2001, p. 3).

Nossa opção para retomar este processo é reproduzir extensamente trechos de uma entrevista concedida, em 6 de dezembro de 2013, por Luiz Carlos Bresser-Pereira a Leonardo Queiroz Leite, e publicada em 2014 na Revista de Administração Pública. Pensamos que compartilhar este valioso depoimento é mais esclarecedor que revisar os textos produzidos sobre o tema, até porque, em sua maioria, são marcados pelos traços evidenciados por Fadul, Silva e Silva (2012). Nosso critério de seleção de trechos foi buscar temas relacionados ao neoliberalismo, ao gerencialismo, à NAP e à continuidade da Reforma, contando com a versão do próprio Bresser-Pereira. Nossa 
opção é não analisar estas declarações tendo como referência os itens anteriores, até porque essa interpretação seria tão óbvia que poderia ofender a inteligência dos leitores e resultaria em um texto redundante.

Respondendo à pergunta sobre o momento no qual surgiu a ideia da Reforma, a resposta é muito esclarecedora sobre o vínculo com as prescrições surgidas nos países anglo-saxões. Vejamos a resposta:

Eu havia lido, uns dois anos atrás, o livro de Osborne e Gaebler, Reinventando o governo, e havia achado muito interessante. Não tinha teoria nenhuma, mas tinha uma história das coisas que estavam acontecendo na administração pública norte-americana que me pareciam muito boas, que faziam toda a lógica, segundo minha visão. Havia outra coisa importante que esqueci de dizer. Desde os anos 1980 eu já tinha clara a ideia da organização social. Contar com organizações mais flexíveis, sem administradores públicos concursados estáveis ou quase estáveis, nas áreas em que não havia poder de Estado envolvido, seria muito bom; implicaria um grande ganho de eficiência. [...] com as ideias do Reinventando o governo e da organização social (que não tinha ainda esse nome), mas eu só completei as minhas ideias, só consegui montar o meu modelo da Reforma, de qual deve ser a organização do Estado moderno, quando eu decidi viajar para conhecer melhor o sistema americano. Mas, por sorte, soube que o Osborne estava em Brasília e o convidei para almoçar (foi a única vez que o vi na vida). Aí eu disse que estava interessado em ir aos EUA e ele me disse que achava melhor que eu fosse à Grã-Bretanha ou à Nova Zelândia (Leite, 2014, p. 1055)

\section{Sobre a viagem à Grã-Bretanha:}

[...] inicialmente eu só tinha notícias dos EUA, e quando ele me deu a alternativa da Grã-Bretanha ou da Nova Zelândia eu escolhi imediatamente a Grã-Bretanha. Então fui à Grã- Bretanha e passei lá três ou quatro dias visitando várias coisas, e quando saí de lá ful a Santiago de Compostela, onde havia uma reunião de administradores públicos, bem ortodoxa. E lá eu falava no último dia, e então, na manhã desse dia, eu sentei com a Ângela Santana e desenhei um quadro [das bolinhas], e apresentei. Foi a primeira vez que eu apresentei aquele modelo que seria o resumo teórico da Reforma (Leite, 2014, p. 1056).

\section{Sobre as missões de cooperação de outros países:}

Quando eu fui à Grã-Bretanha, já havia a ideia de uma assistência, um sistema de ajuda que os países ricos dão a países em desenvolvimento. Então eu fui lá, conversei com eles, conheci a Kate Jenkins, uma ex-alta servidora do governo inglês que havia gerido o primeiro programa da Reforma Gerencial Britânica, chamado "Next Steps", em 1987. Em julho de 1995, a Kate [na condição de uma consultora privada, pois nessa época já não estava mais contratada pelo governo britânico] veio com um grupo de consultores e fizeram um seminário durante uns dois ou três dias, muito interessante. E depois disso ela passou a vir sistematicamente para dar consultoria para a Reforma. Porque eu declarava sempre, e isso está em todo lugar, que eu estava me baseando na experiência que começou na Grã-Bretanha em 1987. Então eu algumas vezes escutava: "Ah, então a Reforma é neoliberal, porque começou no governo da Margareth Thatcher". E eu respondia: "é verdade que foi no Governo Thatcher, mas também é verdade que naquele mesmo período começou uma reforma igual na Nova Zelândia e na Austrália, que naquele momento tinham governos trabalhistas" (Leite, 2014, p. 1064-5)

Não há dúvidas das fontes de inspiração e da imediata apropriação/operacionalização das ideias com as quais havia tido contato recente, sustentadas depois por uma cooperação continuada, apesar das inúmeras vezes em que Bresser-Pereira professa a originalidade de suas proposições e o distanciamento da NAP. Também começa a ficar evidente a forma simplificada, quase rudimentar para um intelectual orgânico com uma trajetória tão significativa, com que aborda o tema do neoliberalismo. Vejamos outro trecho da entrevista:

Essa estória de neoliberalismo me deu trabalho, porque o governo FHC, especialmente na área econômica e na área das questões nacionais, foi neoliberal. As privatizações, por exemplo, de atividades públicas monopolistas, que não se deve privatizar. Infelizmente era o pensamento dominante na ocasião, e o governo FHC entrou gostosamente nessa área. Eu só fui criticar isso muitos anos depois, porque eu não podia criticar dentro do governo ou logo depois que saí. Então isso me deu trabalho. Para você não ser neoliberal, você não precisa defender o burocratismo (Leite, 2014, p. 1060).

Em uma entrevista anterior, dada em abril de 2011 ao Valor Econômico disse Bresser-Pereira: "No governo Fernando Henrique, ou nos anos 90, a hegemonia neoliberal foi muito violenta. Foi tão violenta que também atingiu a mim. Não escapei dela".

É interessante perceber, talvez por essa contaminação involuntária da hegemonia neoliberal, como ele elege a burocracia pública como problema e o mercado como solução, ao justificar o caráter da reforma pela suposta ineficiência das organizações públicas:

E finalmente há a área social, que não tem nem recursos e nem capacidade administrativa. E essa é a área que eu afirmei ter absoluta prioridade para tentar ajudar, ou seja, a educação, a saúde e a previdência. Era isso que me interessava. Os grandes serviços públicos prestados nessa área que definem o Estado social, porque são serviços caros, e é para administrar bem esses serviços que as organizações sociais são tão importantes (Leite, 2014, p. 1059).

Também é muito esclarecedor o relato que faz sobre os apoios chave para o sucesso do convencimento sobre a reforma:

O Antônio Britto ${ }^{i v}$, por exemplo, que era governador do Rio Grande do Sul, entre outros. [...] Houve um almoço com o Michel Temer, por exemplo, que foi muito importante, porque ele me ajudou com ideias de como fazer um bom compromisso com o Congresso. Havia também o líder do governo na Câmara, na época, o Inocêncio de Oliveira, que era um deputado muito inteligente (sem o nível intelectual do Temer, evidentemente), mas um homem muito esperto que sabia da política (Leite, 2014, p. 1061).

Para diferenciar-se da NAP (usando a expressão em língua inglesa New Public Management - NPM) e afirmar sua contribuição original, retoma sua "rejeição" (sic) do neoliberalismo:

Então, minha reforma estava adaptada à realidade do Brasil — isto muito deliberadamente da minha parte. Não estava absolutamente interessado em copiar ideias, mas eu não queria rejeitar boas experiências. Por outro lado, a Reforma tinha um caráter estrutural que não estava claro nos textos do NPM [...]. Eu desenvolvi toda uma teoria que fazia uma análise estrutural dos tipos de propriedade, distinguia a propriedade estatal da pública não estatal, e localizava nesta as organizações sociais. Creio que não havia esse caráter estrutural na NPM. Seus autores estavam mais preocupados em transferir as estratégias de gestão privada para a administração pública. Minha posição em relação à NPM era contraditória. De um lado via nela semelhanças com o modelo ou teoria que eu havia desenvolvido sobre a organização do Estado e tinha interesse em mostrar que a Reforma de 1995 fazia parte de uma mudança mundial — da Reforma Gerencial que nos países ricos acontecia cerca de 100 anos depois, quando o Estado passa a ser social da primeira reforma: a Reforma Burocrática. De outro, eu via nela uma certa orientação neoliberal que eu rejeitava (Leite, 2014, p. 1065)

É muito interessante como Bresser-Pereira consegue, em um mesmo raciocínio, afirmar o caráter estrutural que criou novas organizações para a prestação de serviços no mercado (criando, na prática, novos mercados) e regidas pela lógica do mercado, e afirmar que rejeita a orientação neoliberal.

Talvez a transcrição que segue esclareça seu raciocínio - uma mistura de um suposto marxismo, determinismo, confusões conceituais, superficialidade e retórica mistificadora: 
Penso assim porque eu tenho uma formação marxista importante, e empreendi a lógica da história com Marx, o materialismo histórico, que, entendido amplamente, é uma coisa fascinante. Eu aprendi que a Reforma Gerencial é uma coisa que ocorre quase inevitavelmente em um país que se torna social-democrático ou que cria um Estado do bem-estar social. E um Estado se torna um Estado do bem-estar social quando se torna democrático, porque os grandes serviços sociais do Estado se tornam uma demanda dos eleitores. [...] Quando você tem uma sociedade democrática, o Estado tende necessariamente a se tornar um Estado do bem-estar social. [...] Dizem que acabaram com o Estado do bem-estar social, mas isso é falso. O que fizeram foi flexibilizar as leis trabalhistas, isso os neoliberais conseguiram. E quando você tem um Estado socialdemocrático, necessariamente você vai ter que fazer uma reforma gerencial, porque esse é um Estado muito grande, que tem grandes servicos que o Estado considera importante oferecer gratuitamente ou quase gratuitamente à população. Em consequência, a reforma gerencial vem mais cedo ou mais tarde. O problema todo é saber, depois que o país se tornou realmente democrático, quanto tempo demora para que ele inicie a Reforma, e com qual qualidade e competência ele a faz. Mas que a Reforma vai acontecer, vai. Logo, a reforma que iniciei está bem-sucedida, está em marcha, porque faz parte da lógica das coisas. Eu me antecipei um pouco, porque o Brasil, que eu saiba, é o único país em desenvolvimento que tem o Estado do bem-estar social (Leite, 2014, p. 1068).

Nesse ponto é preciso dizer que temos alguma concordância com Bresser-Pereira. A Reforma está em marchav. Para além de 1995, do Plano Diretor e de sua expressão legal é preciso considerar as alterações constitucionais (em especial a EC 19/1998) e o conjunto de leis que, de fato, mudaram a organização do Estado brasileiro, tais como as mudanças no Regime Jurídico Único e a instituição do emprego público, a supressão da revisão salarial anual dos servidores públicos, a legalização das privatizações/concessões, a introdução da cultura do desempenho e das avaliações de cunho produtivista, o movimento da qualidade total na AP, a consolidação da responsabilidade fiscal desconectada da oferta de serviços e das necessidades sociais, o uso de entes privados para a prestação de serviços públicos, a contratualização como forma de relação, inclusive entre entes públicos, a flexibilização da AP e a disseminação da terceirização. Esses traços marcantes foram, desde então, sendo gradativamente implementados nos diferentes níveis de governo e avançando, inclusive, em áreas que Bresser considerou como seus "grandes fracassos - as universidades e os hospitais públicos":

Um grande fracasso meu foi a reforma das universidades. O que o governo federal tinha de grande que podia se transformar em organização social? Em primeiro lugar estavam as universidades. [...] Além disso, havia os hospitais federais, que foram minha segunda prioridade, mas a maioria dos hospitais estava dentro das universidades. $E$ eu tentei fazer isso. [...] É por isso que temos um modelo atrasado de universidade pública no Brasil. É principalmente por isso que nossas avaliações internacionais são tão medíocres (Leite, 2014, p. 106).

Mas os governos petistas levaram estas ideias adiante. No caso da universidade, deram passos largos. Para começar, o Plano de Reestruturação e Expansão das Universidades Federais (REUNI) definiu um novo padrão de intervenção (Brasil, 2007) que elimina, definitivamente, qualquer possibilidade de exercício do princípio constitucional da autonomia universitária. $\mathrm{Na}$ prática, as universidades estão submetidas a uma modalidade de contrato de gestão que entrou de contrabando no bojo do Reuni - uma espécie de experimento que transformou as universidades federais em organizações administradas por um contrato por meio do qual o governo central estabelece metas e indicadores de desempenho (taxa de conclusão dos cursos de graduação e relação de alunos por professor, p. ex.) que, inclusive, determinam os termos da renovação do contrato (Andrade et al., 2011). O funcionamento da educação a distância através de financiamentos da Universidade Aberta do Brasil segue os mesmos mecanismos de contrato de gestão. É preciso, ainda, vincular essa prática à destinação de recursos públicos para organizações privadas (via FIES e PROUNIvi); e à extinção de cargos nas atividades meio e a imposição, na prática, da terceirização. Em 2016 temos, para complementar, a criação do Código de Ciência, Tecnologia e Inovação que, entre outras alterações, permite transformar os quadros da Universidade em quadros da terceirização da Pesquisa e Desenvolvimento nas empresas, através da oferta da infraestrutura e do conhecimento presente nas universidades e instituições de pesquisa à disposição dos interesses do setor produtivo empresarial. Não esqueçamos o balão de ensaio do Presidente da CAPES em 2014, propondo a contratação de docentes para instituições federais de ensino superior por meio de organizações sociais que seriam criadas pelo Ministério da Educação e do Ministério de Ciência, Tecnologia e Inovação (Neto, 2014).

No caso dos hospitais públicos, os governos petistas foram bem-sucedidos onde Bresser-Pereira havia fracassado. A Empresa Brasileira de Serviços Hospitalares (EBSERH) foi criada através da Lei Federal 12.550 de 15 de dezembro de 2011. Misoczky (2002), já havia defendido a existência de uma contrarreforma no âmbito do Sistema Único de Saúde e mostrado como os preceitos da reforma do aparelho de Estado transitaram facilmente sob o discurso da manutenção da saúde como direito. Andreazzi (2013, p. 280), por sua vez, registra o peso das restrições orçamentárias na indução do crescimento do mercado privado e da expansão das organizações sociais. A criação da EBSERH se insere neste contexto e, além de transformar a atividade de ensino, pesquisa e assistência dos hospitais universitários em atividade econômica, implementa o princípio do plano de negócios para definir o perfil da empresa, o que, "em uma conjuntura de prolongado ajuste fiscal, significará a incessante busca de recursos privados". Além disso, estabelece a necessidade de contratos de prestação de serviços com as universidades em uma "terceirização de atividades-fim", mais uma vez violando o princípio constitucional da autonomia universitária. Esse princípio também é eliminado pelo fato de que a EBSERH se torna coordenadora e avaliadora da execução das atividades dos hospitais universitários. Trata-se, ainda, de uma ameaça "à universalidade do direito à saúde e à gratuidade do sistema público", assim como uma "acelerada mercantilização da atenção à saúde, subordinada progressivamente aos interesses dos grandes capitais internacionais e seus sócios internos" (Andreazzi, 2013, p. 282).

\section{Considerações Finais}

Em uma tentativa de superar essas limitações, evidenciamos a interconexão indissociável entre o processo de reformas, as 
transformações resilientes do neoliberalismo e a emergência de seu braço operacional - o gerencialismo - no marco da segunda mutação das TOs. Enquanto projeto de classe, o neoliberalismo se renova para garantir a estratégia de acumulação através da busca constante pela completa subordinação da reprodução social ao mercado. Isso se expressa enquanto tática na AP por meio das reformas continuadas do aparelho de Estado, um processo marcado por múltiplas possibilidades irradiadas a partir do gerencialismo, objetivando a abertura de novas frentes para acumulação de capital dentro e fora da máquina de Estado, seja por meio de transformações internas ou de relações com organizações privadas. O gerencialismo é, portanto, a matriz teórico-ideológica que oferece o suporte operacional para o avanço do projeto neoliberal.

Por que insistir na importância de contextualizar as reformas continuadas nos marcos do neoliberalismo e do gerencialismo, para além das concepções simplificadoras (redução do Estado e contaminação do público pelo privado)? Porque se adotarmos o mito do pós-neoliberalismo corremos o risco de "nos jogar aonde já caímos", como diz Moska em sua canção (Tudo de novo). O fato de escrevermos no contexto de um governo usurpador não autoriza que mistifiquemos o passado recente. Aliás, para avançar em seus projetos contra a classe trabalhadora, o governo Temer e seus aliados não precisam de nenhuma reforma organizacional do aparelho de Estado. Basta usar a estrutura posta em cena pelos governos anteriores.

Portanto, não se pode tratar este tema sob a suposição de que basta constatar maior presença estatal ou a existência de algumas políticas distributivas para afirmar que 0 neoliberalismo foi superado. É preciso considerar o significado das posições heterodoxas e seus significados essenciais em termos de disputas entre as classes sociais.

Se não o fizermos, corremos o risco de tomar proposições do tipo neodesenvolvimentista, com presença marcante do Estado, como desconectadas do neoliberalismo. Por exemplo, BresserPereira (2010) vislumbra a globalização como uma oportunidade para países como o Brasil em um projeto de reindustrialização em coalizão com o agronegócio, que proveria os fundos para a reindustrialização. Nos termos de Katz (2015), uma solidariedade capitalista do latifúndio oligarca exportador com as elites urbanas, com o usual estímulo ao consumo. Este não é o espaço para avançar neste tema. Mencionamos apenas para chamar atenção para as dificuldades com que nos deparamos quando tomamos os fenômenos e propostas supostamente alternativas sem submetêlos ao escrutínio crítico.

Encerrando este ensaio que, como tal, não obriga conclusões e recomendações, reiteramos a importância da ampliação teórica no campo da AP, e de uma maior aproximação com as TOs, para as quais a maioria dos pesquisadores de AP tem sistematicamente virado as costas.

\section{Referências}

Alves, E. (2001). Uma análise crítica do Plano Diretor da Reforma do Aparelho do Estado. Revista Acadêmica Multidisciplinar Urutágua, 1 (3), 1 14.

Andrade, D.C.T. et al. (2011). A Gestão Pública e o REUNI: Entre o Social e o Gerencial. Unincor. Três Corações, MG, 9 (2).

Andreazzi, M. F. S. (2013). Empresa Brasileira de Serviços Hospitalares: inconsistências à luz da Reforma do Estado. Revista Brasileira de Educação Médica, (32) 2, 275-284

Andrews, C. (2010). Da década perdida à reforma gerencial: 1980-1998. In Andrews, C.; Bariani, E. (Orgs.). Administração Pública no Brasil: breve história política. São Paulo: Editora Unifesp.

Birdsall, N., \& La Torre, A. de. (2001). El Disenso de Washington:políticas económicas para la equidad social en Latinoamérica. Fondo Carnegie para La Paz Internacional y Diálogo Interamericano. Washington, D.C. Recuperado

http://carnegieendowment.org/pdf/files/er.Contentious.SummaryinSpanish.p df. BRASIL. (1995). Ministério da Administração e Reforma do Estado. Plano Diretor da Reforma do Aparelho de Estado. Brasília.

(2007). Ministério da Educação. Secretaria da Educação Superior. Diretrizes gerais do Programa de Apoio a Planos de Reestruturação Expansão das Universidades Federais - REUNI. Brasília.

Bresser-Pereira, L. C. (2008). O modelo estrutural de gerência pública. Revista de Administração Pública, 42 (2), 391-410.

(2010). Democracia, Estado social e reforma gerencial. Revista de Administração de Empresas, 50 (1), 112-116.

Drucker, P. (1999). Sociedade pós-capitalista. São Paulo: Pioneira.

Fadul, E. M.; Mac-Allister da Silva, M.; Silva, L.P. (2012). Ensaiando interpretações e estratégias para o campo da administração pública no Brasil. Revista de Administração Pública, 46 (6), 1437-58.

Fadul, E. M.; Silva, L. P. Retomando o debate sobre a Reforma do Estado e a Nova Administração Pública. Anais do XXXII Encontro da Anpad, 2008.

Gambina, J. C. (2015). Consideraciones a propósito del "neo-desarrolismo". Anauário de Estudios Políticos Latinoamericanos, (2), 75-96.

Harvey, D. (2007). Neoliberalismo como destruição criativa.Interfacehs Revista de Gestão Integrada em Saúde do Trabalho e Meio Ambiente, 2 (4).

Katz, C. (2015). ¿Qué es el neo-desarrollismo? Una visión crítica. Anauário de Estudios Políticos Latinoamericanos, (2), 49-74.

Klikauer, T. (2013) What is managerialism. Critical Sociology, 41(7-8), 1103119.

Leite, L. (2014) Reflexões de um reformador contemporâneo do Estado brasileiro : entrevista com Luiz Carlos Bresser-Pereira. Revista de Administração Pública, 48 (4),

Lukács, G. Por uma ontologia do ser social. Vol. 1. Campinas: Boitempo, 2012.

Macdonald, L., \& Ruckert, A., 2009. Post-Neoliberalism in the Americas. Basingstoke, UK: Palgrave Macmillan

Misoczky, M. C. (2002). A produção social no campo da atenção à saúde após a Constituição de 1988: uma narrativa de sua produção social. Porto Alegre: Dacasa.

(2014). Administração Pública Contemporânea. Porto Alegre: Ministério da Cultura/UFRGS/EA, Módulo 4. Apostila do Curso de Extensão em Administração Pública da Cultura.

(2016). Teorización organizacional: de las mutaciones funcionales a las posibilidades de una crítica ontológica. Texto inédito.

Moreno, A.C. (2015) Gasto do governo com Fies em 2015 já soma 52\% do orçamento previsto. G1 Educação. Recuperado de http://g1.globo.com/educacao/noticia/2015/07/gasto-do-governo-com-fiesem-2015-ja-soma-52-do-orcamento-previsto.html

Neto, L. (2014). MEC planeja criar OS para contratar pesquisadores internacionais para universidades federais. Recuperado de http://oglobo.globo.com/sociedade/educacao/mec-planeja-criar-os-paracontratar-pesquisadores-internacionais-para-universidades-federais14009778\#ixzz4aMmrieWL

Ostrom, E. (1990). Governing the common: the evolution of institutions for collective action. Cambridge, New York: Cambridge University Press.

Prestes Motta, F. C. (2001). Teoria das organizações: evolução e crítica.São Paulo: Pioneira Thomson Learning

Puello-Socarrás, J. F. (2008). Nueva Gramática del Neo-liberalismo. Itinerarios teóricos, trayectorias intelectuales, claves ideológicas. Bogotá: Universidad Nacional de Colombia, Facultad de Derecho, Ciencias Políticas y Sociales, 
(2013a). Ocho tesis sobre el neoliberalismo (1973-2013). In: RAMÍREZ, Hernán. O neoliberalismo Sul-americano em clave transnacional: enraizamento, apogeu e crise (pp. 13-57). São Leopoldo: Oikos - Unisinos.

(2013b). Breve historia del anti-neoliberalismo: economía política sudamericana y paradigmas de desarrollo en el siglo XXI. Anauário de Estudios Políticos Latinoamericanos, 1, 167-186.

(2015a). Neoliberalismo, antineoliberalismo, nuevo neoliberalismo: episodios y trayectorias económico-políticas suramericanas (1973-2015). In: VILLAGRA, L. R. (Coord.). Neoliberalismo en America Latina: crisis, tendencias y alternativas (pp. 19-42). Buenos Aires: Clacso.

. (2015b). Desarrollo: paleontología (política) de una idea (neoliberal). Anauário de Estudios Políticos Latinoamericanos, (2), 13-48.

(2015c). El "eco" del Papa Francisco: laudato si, neoliberalcatolicismo y ecología social de mercado. 27 de junho de 2015. Recuperado de http://puello-socarras.webnode.com.ar/news/el-eco-del-papa-franciscode http://puello-socarras.webnode.com.ar/news/el-eco-del-papa-
laudato-si-neoliberal-catolicismo-y-ecologia-social-de-mercado/.

(2016). Las críticas neoliberales al neoliberalismo: el dogma de mercado y las herejías que nunca llegan a convertirse en blasfemias Rebelión recuperado de: http://www.rebelion.org/noticia.php?id=214205

., \& Gunturiz, M. A. (2013). ¿Social-neoliberalismo? Organismos multilaterales, crisis global y programas de transferencia monetaria condicionada. Política y Cultura. México: Universidad Autónoma Metropolitana - Xochimilco, 40, 29-54.

Rosenstein-Rodan, P.N. (1984). Natura facit saltum: analysis of disequilibrium growth process. In: MEYER, G. M. \& SEERS, D. Pioneers in development. Washington DC: Oxford Press.

' Um dos fundadores da teoria do desenvolvimento. Ver: Rosenstein-Rodan (1984).

iiPuello-Socarrás (2015c) sintetiza a diferença entre a economia de mercado (neoliberalismo anglo-saxão e norte-americano - "posturas hegemônicas consideradas extremistas, mas que ainda prevaleceram durante o século XX") e o neoliberalismo alemão "através da distinção entre um neoliberalismo selvagem e um neoliberalismo do bom selvagem (isto é, com algo de 'inclusão social", ambos, no final, neoliberalismos.

iii O mais conceituado período da área de AP no Brasil segundo critérios do Qualis Capes.

ivGovernador do Rio Grande do Sul de 1995 a 1998, por meio de incentivos fiscais exorbitantes (revertidos no governo seguinte) 'conquistou' a instação de fábricas da Ford e a GM, adotou uma política concessiva de direcionamento dos tributos, produziu 13 alterações no Fundopem ampliando
Sader, E. (2008). Postneoliberalismo en América Latina. Buenos Aires: CLACSO.

(2013). Apresentação. In: SADER, Emir (org.). 10 Anos de Governos Pós-Neoliberais no Brasil: Lula e Dilma (pp. 7-9). São Paulo e Rio de Janeiro: Boitempo e FLACSO Brasil.

Simon, H. (1947). Administrative behavior: a study of decision-making processes in administrative organization. New York: MacMillan.

A; Smithburg, D. W.; Thompson, V. A. (1950). Public Administration. New York: Alfred A. Knopf.

Stiglitz, J. (1998). Redefining the Role of the State: What should it do? How Should it Do it? And How should these decisions be made? Tenth Anniversary of MITI Research Institute. Recuperado de http://people.ds.cam.ac.uk/mb65/library/stiglitz-1998.pdf.

Tirole, J. (2005). Sin um regulador flerte, no hay liberalización eficaz.El País.Recuperado http://elpais.com/diario/2005/12/25/negocio/1135520066_850215.html.

Tragtenberg, M. (1980). Administração, poder e ideologia. São Paulo: Moraes.

Willianson, J. (2004). A Short History of the Washington Consensus. Barcelona: Fundación Cidob. Recuperado de http://www.iie.com/publications/papers/williamson0904-2.pdf.

Wilson, W. (1953). The study of administration. In: WALDO, D. Ideas and issues in Public Administration: a book of readings (pp. 65-75). Westport: Greenwood Press.

suas concessões em mais de $R \$ 1,5$ bilhão $(R \$ 1,1$ bilhão destinado à indústria fumageira), vendeu o patrimônio público (a parte mais lucrativa da Cia. Estadual de Energia Elétrica e a Cia. Riograndense de Telecomunicação - curiosamente para o grupo Telefónica, aonde foi trabalhar quando derrotado na tentativa de reeleição), aumentou o ICMS de 12 para $18 \%$, deixou o governo com uma dívida de $\mathrm{R} \$ 10$ bilhões.

"Na entrevista ele menciona a grande contribuição de Antônio Anastasia ("foi meu assessor também, um assessor voluntário) quando Secretário de Planejamento do primeiro governo de Aécio Neves em Minas Gerais, "eles, juntos, realizaram o Choque de Gestão que foi uma bela realização" (em Leite, 2014, p. 1069).

vi O Prouni e o Fiesmovimentaram aproximadamente $R \$ 15$ bilhões de reais em 2015 (Moreno, 2015). 